\title{
A SOBERANIA E O DIREITO TRIBUTÁRIO INTERNACIONAL
}

Márcio Ávila ${ }^{1}$

\begin{abstract}
RESUMO
O presente artigo expõe as formas de manifestação da soberania no Direito Tributário Internacional. Existem diversas maneiras de se violar a soberania tributária dos Estados e a principal forma de combate é a adoção das normas anti-elisivas.
\end{abstract}

PALAVRAS-CHAVE: direito tributário internacional. Soberania. Norma anti-elisiva.

\begin{abstract}
This article discusses the various manifestations of sovereignty in International Tax Law. There are several ways to violate the tax sovereignty of states and the main form of combat is the adoption of anti-avoidance rules.
\end{abstract}

KEY WORDS: international tax law. Sovereignty. Anti-avoidance rule.

\section{INTRODUÇÃO}

A soberania tributária é aspecto da soberania no seu sentido mais amplo e no Direito Tributário Internacinal pode ser analisada tanto sob o ângulo das leis tributárias internas quanto das Convenções Contra a Dupla Tributação (CCDTs). Compete ao Direito Internacional Público determinar se a conexão com a soberania é "forte" ou "fraca".

Quanto às leis tributárias internas, interessa saber até que ponto elas podem alcançar situações plurilocalizadas. Muito frequentemente, o limite apenas será determinado no caso concreto. Violará a soberania, por exemplo, uma lei que pretenda tributar um não-residente que aufira rendimentos em território estrangeiro, porque nesse caso inexiste qualquer conexão com o território nacional.

\footnotetext{
${ }^{1}$ Mestre e Doutorando em Direito Internacional pela UERJ. Professor de Planejamento Tributário Internacional na Pós-Graduação em Direito Financeiro e Tributário da UFF. Consultor jurídico da PETROBRAS. Advogado no Rio de Janeiro.

Artigo recebido em: 16/05/2011 aprovado em 18/01/2012.
} 
No que concerne às CCDTs, a própria capacidade dos Estados em celebrá-las já implica numa manifestação da soberania tributária. A renúncia parcial ou total de determinado rendimento também expressa a soberania.

\section{Princípios da territorialidade e da universalidade}

Através da soberania tributária podem ser extraídos dois grandes princípios da tributação internacional: a territorialidade e a universalidade.

\subsection{Princípio da territorialidade}

O princípio da territorialidade, fundado na soberania territorial, significa que a tributação incidirá sobre fatos que tenham ocorrido no território de um dado país, ainda que o beneficiário do rendimento seja não-residente.

O Estado que adota o princípio da territorialidade não tributa os rendimentos auferidos por seus residentes no exterior. As jurisdições eminentemente importadoras de capital costumam adotar esse princípio. Na América Latina, o Paraguai é exemplo de país que adota a territorialidade. Segue abaixo, ilustração dos efeitos do princípio em estudo:

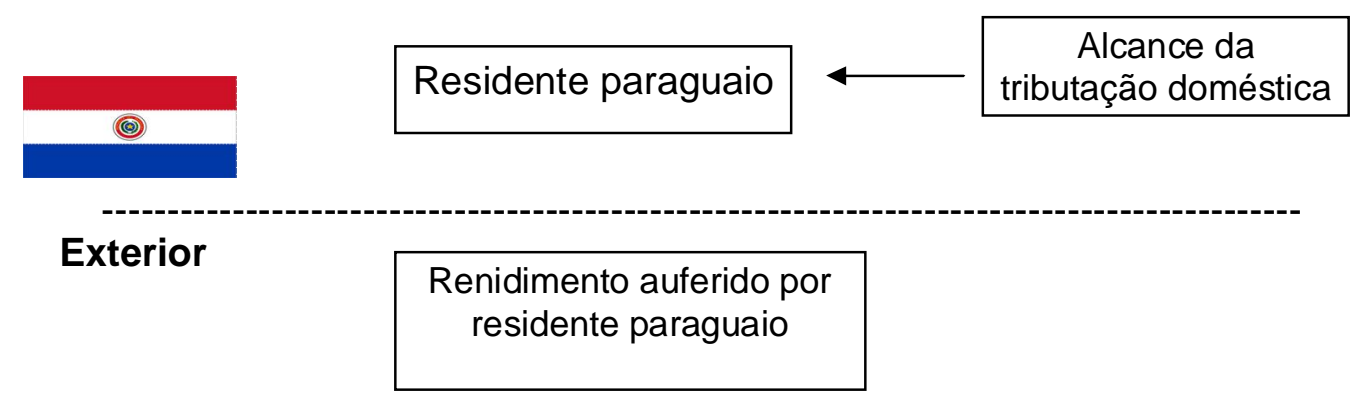

Como é possível perceber, a tributação baseada no princípio da territorialidade não provoca o fenômeno da dupla tributação internacional da renda. Afinal, se cada Estado tributasse apenas a renda auferida em seu território, não existiria o problema da cumulação de competências tributárias.

\subsection{Princípio da universalidade}

O princípio da universalidade da tributação, adotado pelo Brasil, alcança rendimentos auferidos por residentes brasileiros no exterior, como pode ser visualizado a seguir: 


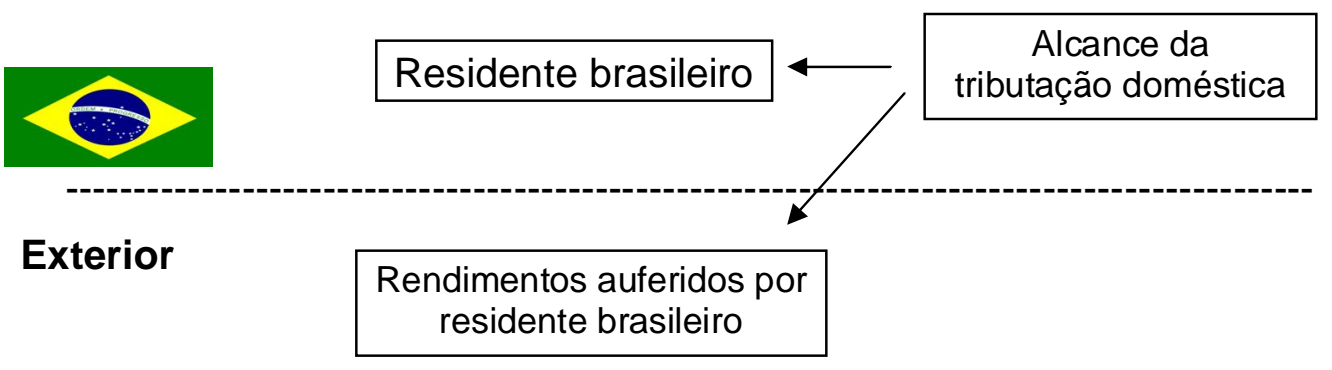

Conforme visto acima, o Estado que adota o princípio da universalidade vai além da tributação territorial. Quando dois ou mais Estados adotam o worldwide income, surge a possibilidade de dupla tributação internacional. Porém, o desenvolvimento das atividades econômicas internacionais não deve tê-la como empecilho ${ }^{2}$. Conforme ensina Antônio de Moura Borges, a questão não é apenas econômica, mas financeira, cultural, sócio-política, de justiça e equidade ${ }^{3}$.

O fenômeno da dupla tributação jurídica internacional surge porque dois ou mais Estados titulares de soberania tributária submetem o mesmo contribuinte, por idêntico objeto, contemporaneamente, a tributos similares ${ }^{4}$. Quando isso ocorre, o movimento de capitais e de pessoas, a transferência de tecnologia e o intercâmbio de bens e serviços ficam prejudicados.

O Direito Internacional Costumeiro não proíbe a dupla tributação ${ }^{5}$. Conseqüentemente, o meio encontrado pelo Direito Internacional para mitigá-la foi a introdução de regras que estabelecessem qual dos Estados envolvidos deveria abdicar do seu direito de tributar ${ }^{6}$.

\footnotetext{
${ }^{2}$ De acordo com o saudoso Klaus Vogel, o Direito da Dupla Tributação é um ramo daquele que é comumente denominado de Direito Tributário Internacional. Cf. a clássica obra: Klaus Vogel on Double Taxation Conventions: a Commentary to the OECD-, UM- and US Model Conventions for de Avoidance of Doublé Taxation if Income and Capital with Particular Reference to German Treaty Practice. Deventer: Kluwer Law and Taxation Publishers, 1991, p. 3.

${ }^{3}$ BORGES, Antônio de Moura. Convenções sobre Dupla Tributação Internacional entre Estados Desenvolvidos e Estados em Desenvolvimento. In: Revista Notícia do Direito Brasileiro. Nova Série. Brasília: Universidade de Brasília, LTr, 1996, p. 77.

${ }^{4}$ A dupla tributação econômica difere da jurídica por ter diversidade de contribuintes, como ocorre com a tributação da pessoa jurídica no Estado "A" e dos sócios no Estado "B", ainda que o acréscimo patrimonial seja um só. As Convenções Contra a Dupla Tributação, em geral, não tratam da dupla tributação econômica internacional.

${ }^{5}$ VOGEL, Klaus. Op Cit, p. 4. Como bem observado por Claudio Sacchetto, um ordenamento (jurídico) incompleto como é o internacional, não permite uma elaboração sistemática de suas fontes em termos exclusivamente "positivos". O costume internacional, constituído pelo comportamento constante e uniforme praticado pelos Estados, é fonte não escrita do direito internacional. SACHETO, Claudio. Las Fuentes del Derecho Internacional Tributario. In: UCKMAR, Victor (Org.). Curso de Derecho Tributario Internacional. Bogotá: Temis, 2003, p. 37 e 38.

${ }^{6}$ A respeito do assunto, Ottmar Buhler já afirmava textualmente: "No se encuentra en los TDI uma cláusula general que declare materialmente ilícita la doble imposición; por el contrario, se trasluce el expresso
} 
A Convenção Contra a Dupla Tributação, espécie de tratado internacional em matéria tributária, procura não apenas eliminar a dupla tributação jurídica internacional sobre rendimentos (v.g. royalties, juros e dividendos), mas também cuida de outros temas caros à manutenção da soberania, como a prevenção à evasão fiscal (v.g. combate ao treaty shopping e cláusula de beneficiário efetivo) e a não-discriminação.

\section{Violações à soberania tributária e normas anti-elisivas}

A soberania dos Estados é constantemente ameaçada quando contribuintes e/ou jurisdições resolvem desenvolver práticas fiscais desleais, tais como: transferência de preços, operações triangulares (treaty shopping) ${ }^{7}$, isenção ou redução substancial da tributação do imposto de renda de empresas estrangeiras, regimes fiscais privilegiados, garantia absoluta de sigilo bancário, subcapitalização de empresas (thin capitalization), etc.

As normas anti-elisivas, estejam estas nas CCDTs ou em normas tributárias internas, têm o efeito prático de neutralizar a violação à soberania tributária dos Estados. A seguir, serão analisadas algumas práticas lesivas à soberania e as correspondentes normas anti-elisivas.

\subsection{Países de tributação favorecida e regimes fisscais privilegiados}

Enquanto a maioria dos Estados utiliza-se do conceito de soberania para justificar a tributação, outras jurisdições aproveitam-se do mesmo conceito para dispensar parte substancial ou toda a incidência tributária, como ocorre com os países de tributação favorecida. Nesse sentido:

\footnotetext{
"Contudo, é curioso notar, é em nome da soberania fiscal que existem sistemas tributários que não utilizam qualquer medida unilateral tendente a evitar práitcas elisivas, tais como o treaty shopping e o preço de transferência. [...]. Inclusive é em nome da soberania tributária que existem os chamados países com tributação favorecida".

(BASSANEZE, João Marcello Trajumas. Pluritributação Internacional: Origem, Conceito e Medidas Unilaterais Destinadas à sua Eliminação. In Direito Internacional Aplicado. TÔRRES, Heleno Taveira. São Paulo: Quartier Latin, 2003, p. 439).
}

mantenimiento de la doble imposición en materias menores cuando no se llega a un acuerdo sobre los mismos". BUHLER, Ottmar. Principios de Derecho Internacional Tributario. Madri: Editorial de Derecho Financiero, 1968, p. 79.

7 É preciso saber se elementos de conexão como a residência, a fonte de produção ou de pagamento são identificados de maneira substancial num caso concreto, de forma a se evitar a configuração de um abuso de conexão 
Os países de tributação favorecida e os regimes fiscais privilegiados, cujas legislações prevêem, na maioria das vezes, sigilo bancário absoluto, terminam por corroer a base tributária de outros Estados, distorcem o comércio e o padrão de investimento e debilitam a justiça, neutralidade e ampla aceitação social dos sistemas tributários (Cf. OECD Report on Harmful Tax Competition - An Emerging Global Issue - 1998) ${ }^{8}$. Ao tratar das medidas para neutralizar a concorrência tributária desleal, a OCDE afirma que os Governos não podem ficar para trás, enquanto suas bases tributárias são corroídas através de ações de países que oferecem aos contribuintes, caminhos para reduzir tributos que seriam, de outro modo, recolhidos para esses mesmos Governos.

Portanto, o abuso da soberania por certos Estados, através de regimes ficais desleais, pode terminar por violar a soberania tributária de outras jurisdições. Conforme observa Michael Graetz, a soberania de uma nação pode ser usurpada pela política tributária de outra ${ }^{9}$.

\subsection{Transferência de preços}

A transferência de preços é o mecanismo utilizado pelo contribuinte para manipular a alocação de receitas ou despesas existentes entre partes residentes em diferentes jurisdições tributárias, para fins, no Brasil, de redução no pagamento do Imposto de Renda (IR) e da Contribuição Social sobre o Lucro Líquido (CSLL). Para aqueles que praticam referida transferência, o que se busca é, fundamentalmente, o seguinte:

\begin{tabular}{|c|c|}
\hline $\begin{array}{c}\text { País com maior carga } \\
\text { tributária }\end{array}$ & $\begin{array}{c}\text { País com menor carga } \\
\text { tributária }\end{array}$ \\
\hline Menor receita & Maior receita \\
\hline Maior despesa & Menor despesa \\
imposição
\end{tabular}

legal do controle dos preços de transferência visa evitar, então, a alocação de prejuízos naquele Estado que apresente maior carga tributária com relação a outro mais atraente para alocar os lucros $^{10}$. Portanto, pode acontecer do subfaturamento nas exportações ou do superfaturamento nas importações - quando os preços praticados, portanto, são divergentes daqueles existentes num regime de livre concorrência -, provocar o seguinte resultado: transferência de base de cálculo para países de menor tributação ou a postergação do pagamento dos tributos.

\footnotetext{
${ }^{8}$ Confira a íntegra do Relatório na obra de Kees Van Raad: Materials on International \& EC Tax Law 2009/2010 (9a. ed. - vol. 1). Rotterdam: International Tax Center Leiden, 2009, p. 1406-1507.

${ }^{9}$ GRAETZ, Michael. Foundations of International Income Taxation. Nova Iorque: Foundation Press, 2003, p. 487

${ }^{10}$ Ávila, Márcio. Preços de Transferência na Indústria do Petróleo (Tranfer Price). Rio de Janeiro: Interciência, 2010, p. 3.
} 
Para Adilson Rodrigues Pires, os preços de transferência se caracterizam pela divergência entre o preço de certa mercadoria, estabelecido entre empresas interdependentes, numa operação de comércio exterior (importação ou exportação), e o valor-teste, entendido como o preço firmado por empresas independentes ${ }^{11}$. No mesmo sentido, Luís Eduardo Schoueri ensina que a legislação de preços de transferência cumpre a função de converter valores expressos em "reais de grupo" para "reais de mercado", o que possibilita a comparação entre contribuintes com igual capacidade econômica ${ }^{12}$.

Alejandro C. Altamirano entende que a problemática dos preços de transferência se funde num verdadeiro problema de repartição e que é justo o fato de os Estados resguardarem a própria capacidade contributiva em situações nas quais a vontade do agente econômico (o contribuinte), contrariamente, se afasta do feixe de luz da imposição, para desnivelar a carga tributária, intencionalmente ${ }^{13}$. Para 0 doutrinador argentino, as diversas definições sobre o tema têm um único denominador comum: a pretensão dos países de anular a perda de capacidade contributiva.

O princípio arm`s length combate a transferência de base de cálculo para países de menor tributação ou a postergação do pagamento dos tributos - verdadeiras distorções na tributação internacional -, impondo às partes vinculadas a obrigação de seguirem os preços praticados de acordo com as condições normais de mercado, ou seja, aqueles desenvolvidos entre partes independentes. Visa-se, portanto, coibir a subtração de rendimentos tributáveis daqueles países onde a riqueza foi efetivamente produzida.

\subsection{Operações triangulares}

As operações triangulares, também conhecidas por treaty shopping, consistem na procura, por parte de um sujeito não-residente (leia-se: empresa-canal, também conhecida

\footnotetext{
${ }^{11}$ PIRES, Adilson Rodrigues. Controle do Preço de Transferência e as Operações de Comércio Exterior. In Tributos e Preços de Transferência ( $2^{\circ}$ vol.) - coord. SCHOUERI, Luís Eduardo e ROCHA, Valdir de Oliveira. São Paulo: Dialética, 1999, p. 12.

${ }^{12}$ SCHOUERI, Luis Eduardo. Preços de Transferência no Direito Tributário Brasileiro (2 ed.). São Paulo: Dialética, 2006, p 15.

${ }_{13}$ ALTAMIRANO. Alejandro C. Precios de Transferencia. In III Coloquio Internacional de Derecho Tributário. Buenos Aires: La Ley-IOB Thomson, 2001, p. 546 e 549.
} 
como conduit company) em relação aos Estados signatários de determinada CCDT, da menor tributação possível em determinada operação internacional.

É possível apresentar um quadro geral das seguintes fases do treaty shopping:

$1^{\text {a }}$ fase: constatação de que os Estados originariamente relacionados à operação internacional não celebraram uma CCDT ou que a Convenção em vigor seja menos favorável;

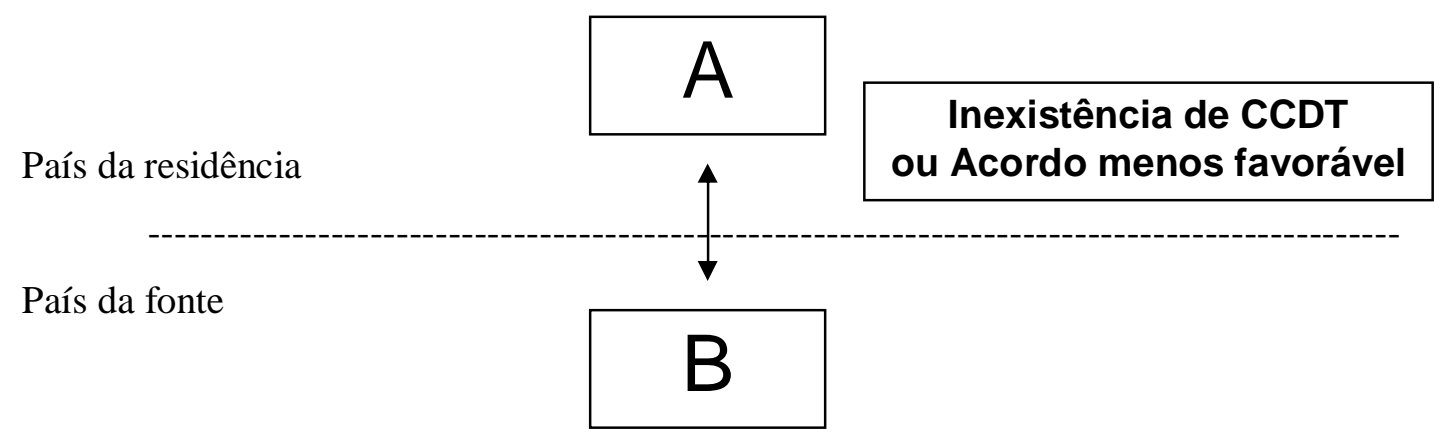

Como consequência da estrutura acima, a retenção do imposto de renda na fonte no país de "B" se dará na integralidade ou em grande medida.

$2^{a}$ fase: procura de jurisdição que tenha celebrado CCDT com o país da fonte do rendimento e, eventualmente, com o país da residência. Nesta jurisdição será interposta uma pessoa física ou jurídica.

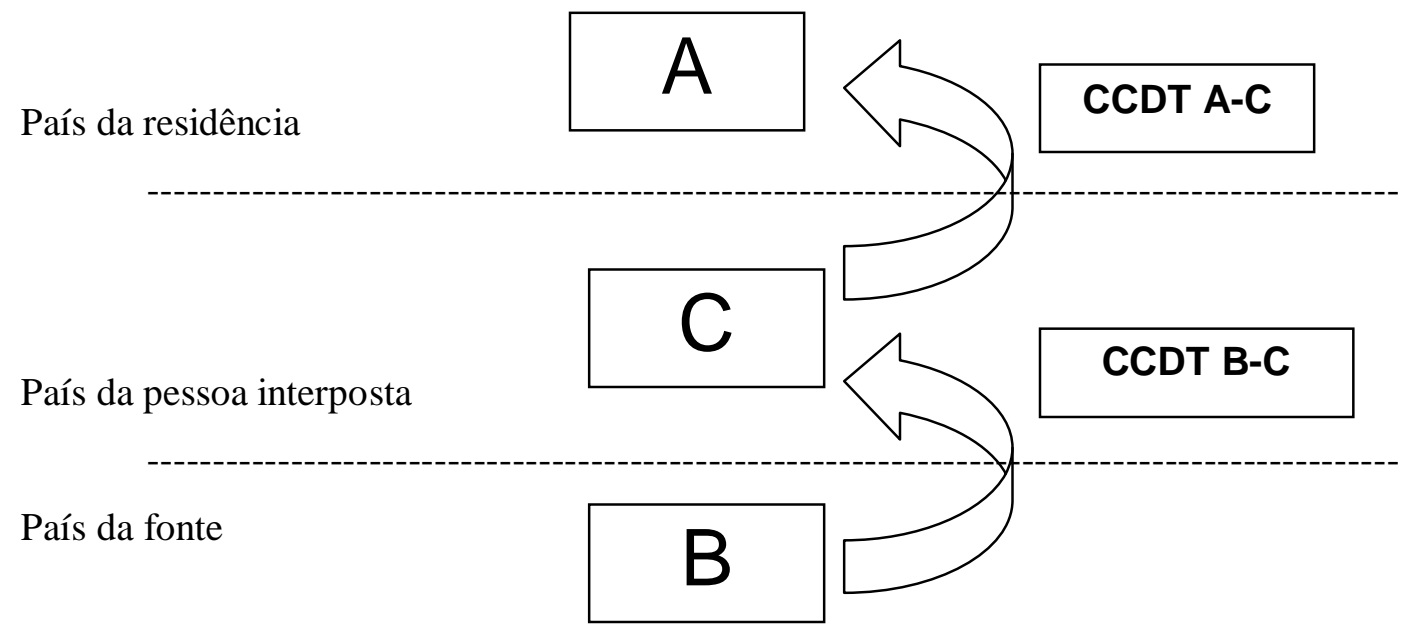


Como consequência dessa estrutura, a retenção do imposto de renda na fonte no país de "B" se dará de forma limitada ou inexistirá, nos termos da CCDT celebrada com o país de "C". Eventual imposto recolhido no país da fonte será considerado no país da pessoa interposta, de acordo o método utilizado para evitar a dupla tributação previsto na Convenção. O mesmo procedimento deve ser observado no repasse do rendimento de "C" para "A", guardadas as peculiaridades da Convenção firmada entre os dois últimos países.

Como "C" foi interposto em jurisdição que celebrou CCDTs tanto com o Estado da fonte quanto com o Estado da residência, passa a ter relevo a questão do beneficiário efetivo do rendimento, que não é “C”, mas “A”. Afinal, a prática do treaty shopping termina por provocar a seguinte situação:

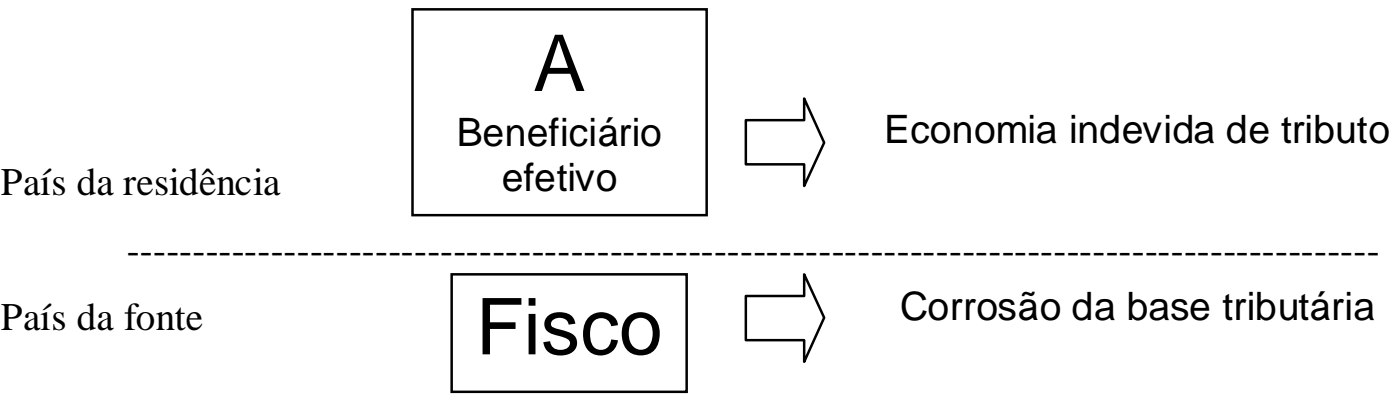

A prática do treaty shopping provoca a criação de normas para o seu controle (cláusula do beneficiário efetivo), de forma a desconsiderar a pessoa interposta e afastar eventuais benefícios fiscais que seriam a ela concedidos caso se tratasse, substancialmente, de um residente fiscal.

A título exemplificatico, na recente Convenção celebrada entre o Brasil e o Perú (Decreto Legislativo $n^{\circ}$ 500/09 e Decreto $n^{\circ}$ 7.020/09), foi possível identificar dez menções à expressão "beneficiário efetivo" no seu texto, o que demonstra a preocupação no combate à interposição artifical de pessoas físicas ou jurídicas com o único fito de economia tributária ${ }^{14}$.

\footnotetext{
${ }^{14}$ Artigo 10 - Dividendos: "1. Os dividendos pagos por uma sociedade residente de um Estado Contratante a um residente do outro Estado Contratante podem ser tributados nesse outro Estado. 2. Todavia, esses dividendos podem também ser tributados no Estado Contratante em que resida a sociedade que os paga e de acordo com a legislação desse Estado, mas, se o beneficiário efetivo dos dividendos for um residente do outro Estado Contratante, o imposto assim exigido não poderá exceder de: a) 10 por cento do montante bruto dos dividendos, se o beneficiário efetivo for uma sociedade que controle, direta ou indiretamente, pelo menos 20 por cento das ações com direito a voto da sociedade que pague os dividendos; (...). 4. As disposições dos parágrafos 1 e 2 deste Artigo não se aplicarão quando o beneficiário efetivo dos dividendos, residente de um Estado Contratante, exerce, no outro Estado Contratante de que seja residente a sociedade que paga os dividendos, uma atividade empresarial por intermédio de um estabelecimento permanente aí situado, ou prestar nesse outro Estado serviços pessoais
} 


\section{Conclusão}

As práticas fiscais desleais são uma constante ameaça à soberania tributária dos Estados. Transferência de preços, operações triangulares, países de tributação favorecida, regimes fiscais privilegiados, jurisdições com garantia absoluta de sigilo bancário, subcapitalização de empresas, etc., todas são formas de corrosão das bases tributárias de inúmeras jurisdições.

Trata-se de um problema de interesse global que deve ser estudado e combatido através de normas anti-elisivas, estejam estas previstas nos acordos para evitar a dupla tributação ou em normas tributárias internas de cada Estado. Apenas dessa forma poderá ser protegida a soberania tributária dos Estados e combatida a concorrência fiscal desleal no âmbito internacional.

independentes por meio de uma base fixa aí situada, e a participação geradora dos dividendos estiver efetivamente ligada a esse estabelecimento permanente ou base fixa. Neste caso serão aplicáveis as disposições do Artigo 7 ou do Artigo 14, conforme as circunstâncias".

Artigo 11 - Juros: 1. "Os juros provenientes de um Estado Contratante e pagos a um residente do outro Estado Contratante podem ser tributados nesse outro Estado. 2. Todavia, esses juros podem também ser tributados no Estado Contratante de que provêm, e de acordo com a legislação desse Estado, mas, se o beneficiário efetivo dos juros for um residente do outro Estado Contratante, o imposto assim exigido não poderá exceder 15 por cento do montante bruto dos juros. (...). 4. As disposições dos parágrafos 1 e 2 não se aplicam quando o beneficiário efetivo dos juros, residente de um Estado Contratante, exercer, no outro Estado Contratante de que provenham os juros, atividade empresarial por intermédio de um estabelecimento permanente aí situado, ou preste serviços pessoais independentes por intermédio de uma base fixa situada no referido Estado, e o crédito em relação ao qual os juros são pagos estiver efetivamente ligado a esse estabelecimento permanente ou base fixa. Em tais circunstâncias, aplicam-se as disposições do Artigo 7 ou do Artigo 14, segundo o caso. 7. Quando, em razão de relações especiais existentes entre o devedor e o beneficiário efetivo, ou entre ambos e terceiros, o montante dos juros pagos, considerando o crédito pelo qual são devidos, exceder o que seria acordado entre o devedor e o credor na ausência de tais relações, as disposições deste Artigo serão aplicáveis apenas a este último montante. Neste caso, a parte excedente dos pagamentos será tributável de acordo com a legislação de cada Estado Contratante, tendo em conta as outras disposições da presente Convenção".

ARTIGO 12 - Royalties: 1. "Os royalties provenientes de um Estado Contratante e pagos a um residente do outro Estado Contratante podem ser tributados nesse outro Estado. 2. Todavia, esses royalties também podem ser tributados no Estado Contratante de que provêm, e de acordo com a legislação desse Estado, mas, se o beneficiário efetivo for um residente do outro Estado Contratante, o imposto assim estabelecido não poderá exceder de 15 por cento do montante bruto dos royalties. (...). 4. As disposições dos parágrafos 1 e 2 deste Artigo não se aplicam quando o beneficiário efetivo dos royalties, residente de um Estado Contratante, exercer, no outro Estado Contratante de que provêm os royalties, uma atividade empresarial por intermédio de um estabelecimento permanente aí situado, ou preste nesse outro Estado serviços pessoais independentes por intermédio de uma base fixa situada em dito Estado, e o bem ou o direito gerador dos royalties estiver efetivamente ligado a esse estabelecimento permanente ou base fixa. Em tais casos, aplicam-se as disposições do Artigo 7 ou do Artigo 14, de acordo com as circunstâncias. (...). 6. Quando, em razão de relações especiais existentes entre o devedor e o beneficiário efetivo, ou entre ambos e terceiros, o montante dos royalties pagos, tendo em conta o uso, direito ou informação pelo qual são pagos, exceder o que seria acordado entre o devedor e o beneficiário efetivo na ausência de tais relações, as disposições do presente Artigo serão aplicáveis apenas a este último montante. Neste caso, a 


\section{Referências bibliográficas:}

ALTAMIRANO. Alejandro C. Precios de Transferencia. In III Coloquio Internacional de Derecho Tributário. Buenos Aires: La Ley-IOB Thomson, 2001.

ÁVILA, Márcio. Preços de Transferência na Indústria do Petróleo (Tranfer Price). Rio de Janeiro: Interciência, 2010.

BASSANEZE, João Marcello Trajumas. Pluritributação Internacional: Origem, Conceito e Medidas Unilaterais Destinadas à sua Eliminação. In Direito Internacional Aplicado. TÔRRES, Heleno Taveira. São Paulo: Quartier Latin, 2003.

BORGES, Antônio de Moura. Convenções sobre Dupla Tributação Internacional entre Estados Desenvolvidos e Estados em Desenvolvimento. In: Revista Notícia do Direito Brasileiro. Nova Série. Brasília: Universidade de Brasília, LTr, 1996.

BUHLER, Ottmar. Principios de Derecho Internacional Tributario. Madri: Editorial de Derecho Financiero, 1968.

GRAETZ, Michael. Foundations of International Income Taxation. Nova Iorque: Foundation Press, 2003.

PIRES, Adilson Rodrigues. Controle do Preço de Transferência e as Operações de Comércio Exterior. In Tributos e Preços de Transferência ( $2^{\circ}$ vol. $)$ - coord. SCHOUERI, Luís Eduardo e ROCHA, Valdir de Oliveira. São Paulo: Dialética, 1999.

RAAD, Kees Van. Materials on International \& EC Tax Law 2009/2010 (9a. ed. - vol. 1). Rotterdam: International Tax Center Leiden, 2009.

SACHETO, Claudio. Las Fuentes del Derecho Internacional Tributario. In: UCKMAR, Victor (Org.). Curso de Derecho Tributario Internacional. Bogotá: Temis, 2003.

SCHOUERI, Luis Eduardo. Preços de Transferência no Direito Tributário Brasileiro (2a ed.). São Paulo: Dialética, 2006.

XAVIER, Alberto. Direito Tributário Internacional do Brasil. Rio de Janeiro: Forense, 2010.

VOGEL, Klaus. Klaus Vogel on Double Taxation Conventions: a Commentary to the OECD-, UM- and US Model Conventions for de Avoidance of Doublé Taxation if Income and Capital with Particular Reference to German Treaty Practice. Deventer: Kluwer Law and Taxation Publishers, 1991.

parte excedente dos pagamentos será tributável de acordo com a legislação de cada Estado Contratante, tendo em 
Revista da Faculdade de Direito da UERJ,V.2,n.22,jul./dez.2012

Pág in a | 11

conta as outras disposições da presente Convenção". 